\title{
Representações sociais sobre a situação de vida, saúde e doença na concepção indígena Potiguara
}

\author{
Social representations about the conditions of life, health and disease according to the Potiguara indians concept
}

A questão da saúde indígena brasileira vem sendo debatida desde a década de 1990, com reivindicações constantes dos indígenas ao governo e à sociedade nacional devido ao agravamento progressivo das condições de saúde deste povo, caracterizado por altos índices de morbimortalidade e pela oferta inadequada e ineficaz dos serviços de saúde. Esta pesquisa teve como objetivos: averiguar a situação de vida, saúde e doença na concepção dos índios Potiguara, salientando as representações sociais interfaceadas aos aspectos epidemiológicos; identificar o perfil socioeconômico, cultural e epidemiológico dos índios participantes deste estudo; apreender representações sociais sobre saúde e doença na concepção dos índios Potiguara; verificar aspectos socioeconômicos e culturais a partir das representações sociais sobre saúde e doença e evidenciar as práticas adotadas pelos índios Potiguara frente à doença. Tratase de uma pesquisa exploratória, documental, com abordagem quanti-qualitativa, tendo como aporte a Teoria das Representações Sociais. A unidade amostral foi definida como sendo o núcleo familiar de acordo com o cadastro das famílias no Sistema de Informação de Atenção à Saúde Indígena (SIASI), sendo identificado 01 membro por família de ambos os sexos e acima de 18 anos. Participaram do estudo 55 famílias sorteadas ao acaso, pertencentes à aldeia São Francisco em Baia da Traição/PB, tomando-se como parâmetro uma tabela de números aleatórios simples para seleção e identificação da família no SIASI. A técnica para coleta de dados foi uma entrevista individual seguida de um roteiro semiestruturado, com questões relativas à caracterização socioeconômica dos participantes, além de questões abertas sobre a temática, com utilização de gravador para registro das informações. Esta pesquisa seguiu as observâncias éticas contempladas nas Resoluções 196/1996 e 304/2000 do Conselho Nacional de Saúde, que tratam da ética em pesquisas envolvendo seres humanos e da temática em especial: população indígena. $O$ tratamento do corpus foi submetido à análise por meio dos softwares: Statistical Package for the Social Sciences
(SPSS) 14.5 e, posteriormente, a Análise Lexical por Contexto de um Conjunto de Segmentos de Texto (ALCESTE) versão 4.8. Os resultados apontam a necessidade das instituições, lideranças indígenas e demais atores que têm responsabilidade social com os índios de se reunirem para adoção de propostas voltadas para a melhoria das condições de vida desta população, em que a Equipe Multidisciplinar de Saúde Indígena promova a integração entre o sistema local de saúde e a sabedoria indígena, tornando, assim, as intervenções de controle mais eficazes, sobretudo em relação às doenças infecciosas e parasitárias. Observamos, por um lado, representações sociais em que os índios Potiguara associam saúde a "ser ou estar saudável" e doença a "ser ou estar doente" capaz de atender às necessidades básicas como: alimentação, assistência à saúde, ocupação, trabalho e moradia. Por outro lado, as representações sociais de saúde e doença são ancoradas nos aspectos econômicos, culturais e sociais. No campo da saúde pública, evidencia-se a relevância deste estudo, uma vez que as representações sociais podem proporcionar fundamentos teóricos contextualizados socialmente para elaboração e avaliação de estratégias e/ou programas adotados pelas instituições responsáveis pela saúde dos índios no Brasil.

Rita de Cassia Cordeiro de Oliveira Dissertação (Mestrado), 2009 Programa de Pós-Graduação em Enfermagem, Universidade Federal da Paraíba rita.oliveira@funasa.gov.br

Palavras-chave: População indígena. Representações sociais. Enfermagem. Processo saúde/doença.

Keywords: Indigenous population. Social representations. Nursing. Health-disease process.

Palabras clave: Población indígena. Representaciones Sociales. Enfermería. Proceso salud-enfermedad.

Texto na integra disponível em:

http://www.ccs.ufpb.br/gepaie/lib/exe/fetch.php?id=hom e\% 3Apublica \% C3\% A7\% C3\% B5es\&cache=cache\&media =home:representa $\%$ C3\% A7\% C3\% B5es sociais sobre a situa \% C3\% A7\% C3\%A3o_de_vida_sa\% C $3 \%$ BAde_e_ doen $\%$ C $3 \% A 7$ a na concep $\%$ C $3 \% A 7 \%$ C $3 \%$ A3o ind\% C3\% ADgeña_potiguara.pdf 